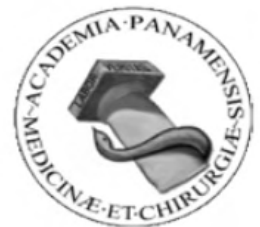

\title{
Comuninaciones Cortas
}

\section{Resumen de las Actividades de la Academia en el año 2018 Academia Panameña de Medicina y Cirugía}

El día 19 de enero de 2018 la Academia Panameña de Medicina y Cirugía, celebró su Sexagésima novena (LXIX Sesión Solemne Anual), en la cual, el secretario presentó un resumen de las actividades de la Academia, durante el año 2017. A partir de febrero, se celebró el tercer jueves de cada mes la Sesión Científica Ordinaria que señala el estatuto, y los trabajos presentados fueron los siguientes:

FEBRERO:

Terapia con células C-A-T en cáncer. Dr. José Franceschi, APMC.

MARZO:

Cancer de mama y anticonceptivos hormonales. Dr. Paulino Vigil A.

ABRIL:

Urgencias Dermatológicas, ¿Realmente existen? Dr. José M. Ríos Yuil (por invitación).

MAYO:

Manejo de las lesiones hepáticas que ocupan espacio. Dr. Mauricio Rodríguez. (Por invitación).

JUNIO:

Evolución de los trasplantes renales en América Central y Caribe Dr. César Cuero, APMC

JULIO:

Características clínicas y epidemiológicas de los pacientes Pediátricos, con Enfermedad renal crónica, estadio 5.

Dr. Basilio Dobras, APMC

AGOSTO: $\quad$ El origen de las enfermedades

Dr. Ícaro Leandro, APMC

SEPTIEMBRE: $\quad$ Medidas basadas en la ejecución en ancianos con historia de caída. Tesis de admisión del Dr. Luis M. Cornejo A.

OCTUBRE: $\quad$ Evaluación clínico radiológico del tratamiento endovascular en Pie Diabético en el Complejo Hospitalario Dr. Arnulfo Arias Madrid, Marzo 2015-junio 2017.

Dr. Jossuet Barrios. (por invitación).

Comentarios Dr. Gilberto Chanis, APMC

NOVIEMBRE: $\quad$ Reunión Administrativa

Informe del Presidente.

Informe del Tesorero.

Informe sobre la revista.

\section{Dr. Edwin R. Acuña O. FACS, APMC \\ Secretario General}

Órgano oficial de la Academia Panameña de Medicina y Cirugía y del Instituto Commemorativo Gorgas para Estudios de la Salud (ICGES). Indexado en LILACS Y EBSCO. 